\title{
Image Edge Detection based on Soft Computing Approach
}

\author{
Pushpajit A. Khaire \\ PG Student, Department of Computer Science \& \\ Engineering, \\ Shri Ramdeobaba College of Engineering \& \\ Management \\ Nagpur
}

\author{
Nileshsingh V. Thakur. \\ Phd, Department of Computer Science \& \\ Engineering Shri Ramdeobaba College of \\ Engineering \& Management
}

Nagpur

\begin{abstract}
Edge detection is one of the most important techniques used for image segmentation. Image segmentation remains a puzzled problem even after four decades of research. In this paper, a soft computing approach based on fuzzy logic is applied on histogram of an image to enhance edge detection technique. We used BSD images for experimentation and their respective ground truths for qualitative evaluation of proposed approach.
\end{abstract}

\section{General Terms}

Image Processing, Segmentation, Experimental Results

\section{Keywords}

Edge detection, Fuzzy Logic, Histogram, Ground Truth, BSD (Berkeley Segmentation Database)

\section{INTRODUCTION}

Image Segmentation process simplifies, further analysis of image by reducing the amount of data to be processed significantly, at the same time useful structural information of object boundaries is preserved. Edge detection is one of the important techniques used for image segmentation. It is a discontinuity based approach for segmentation of digital images. An Edge is a sudden change in the pixel intensity of $t$ image, It contains the critical characteristics and important features of an image. An edge is a boundary between the object and its background. Edge detection is most common approach to detect discontinuity in an image. Many traditional edge detection methods such as Sobel, Prewitt, Kirsch and Robert have a major drawback of being very sensitive to noise. Canny proposed a method which is able to detect both strong and weak edges and seems to be more suitable to detect edges in noisy images. There are numerous applications of image segmentation like Remote sensing, Analysis of medical images, Industrial machine vision for product assembly and inspection, Automated target detection and tracking, Fingerprint recognition, Face Recognition, Astronomical study etc. As a result it remains an active area of research.

\section{RELATED WORK}

Research on image segmentation is currently conducted in three levels.1) Development of image segmentation algorithms.2) Evaluation of segmentation algorithms.3) Performance and study of evaluation methods. J Patel and et al. in [1] proposed an algorithm based on fuzzy systems and fuzzy rules. Using Sobel and Lapalacian approaches first edge values are computed and applied to fuzzy system. The approach reduces false edge detection and detection of multiple responses to a single edge.

An algorithm to detect continuous and smooth edges using particle swarm optimization was proposed by Mahdi Setayesh and et al. in [2].The result showed that the algorithm performs better and less sensitive to impulsive noise than Canny. The algorithm takes much longer time to execute when compared to Canny's approach. Abdallah A. Alshennawy, and Ayman A. Aly in [3] proposed a fuzzy logic technique for edge detection without determining the threshold value. The image is segmented into $3 \times 3$ binary matrix. The algorithm works well and gives line smoothness and straight for the straight lines, corners get sharper and less detection of double edges when compared to Sobel method. An approach for edge detection using independent component analysis is proposed by Kaustubha Mendhurwar and et al. in[4] The proposed approach works well under noisy conditions when compared with Canny .Song Wang and et al.[5]introduced an approach for evaluating edge detection by checking the likelihood of object boundaries from the detected edges. The performance evaluations show that the performance of Sobel, Log, and Canny is very similar. However the default parameters in these methods not best suited for boundary detection. The problem arises with traditional approaches and soft computing approaches applied on methods like (Canny, LOG, Sobel) gives better performance, on noisy images. But due to filtering on image, results in more blurring. Hence, smaller edges are not preserved and the actual edge location is shifted due to blurring operation. The comparative analysis of these algorithms is given in Table 1.

\section{EDGE DETECTION USING IMAGE HISTOGRAM BASED ON FUZZY LOGIC}

Fuzzy Logic based Edge Detection using histogram of an image is proposed in this paper. BSD color images are used for experimentation. The algorithm steps are as follows.

Step1: In Psychological terms, when humans view a color object, we tend to describe it by its hue, saturation and brightness. Keeping in mind these terms first RGB color image is converted into HSI image.

Step 2: The saturation component is removed from obtained HSI image and Histogram of image with hue and intensity is obtained.

Step 3: Fuzzy logic is applied on the obtained histogram, where peaks are taken as membership value 1 . The other bars in the histogram having membership values greater than 0.8 and having difference between gray values less than 32 are added to the peaks to get a valley for segmentation.

Step 4: Finally a $4 \times 1$ operator in both horizontal and vertical directions is convolved with partially segmented image obtained in step 3 to get final output edged image. 
Table 1: Comparison of Methods

\begin{tabular}{|c|c|c|c|c|c|c|}
\hline $\begin{array}{c}\text { Sr } \\
\text { No. }\end{array}$ & Source & $\begin{array}{c}\text { Nature of } \\
\text { Algorithm }\end{array}$ & $\begin{array}{c}\text { Ground } \\
\text { Truth } \\
\text { Evaluation }\end{array}$ & $\begin{array}{c}\text { Algorithms } \\
\text { Compared }\end{array}$ & $\begin{array}{c}\text { Performance } \\
\text { Evaluation } \\
\text { Parameter }\end{array}$ & Findings \\
\hline 1 & $\begin{array}{c}\text { J Patel and } \text { et al., } \\
\text { ICWET'11, ACM } \\
2011 .\end{array}$ & $\begin{array}{c}\text { Fuzzy Logic using } \\
\text { Sobel and LOG. }\end{array}$ & No & LOG, Sobel & None & $\begin{array}{c}\text { Reduces false edge } \\
\text { detection }\end{array}$ \\
\hline 2 & $\begin{array}{c}\text { Mendhurwar and } \text { et } \\
\text { al. Eurasip journal } \\
\text { ISRN Signal } \\
\text { processing.2011 }\end{array}$ & $\begin{array}{c}\text { Edge detection in } \\
\text { noisy images using } \\
\text { independent } \\
\text { component analysis. }\end{array}$ & No & Canny & PSNR & Robust to noise, \\
\hline 3 & $\begin{array}{c}\text { Abdallah A. } \\
\text { Alshennawy, and } \\
\text { Ayman A. Aly, 2009. }\end{array}$ & $\begin{array}{c}\text { Fuzzy logic on } 8 \\
\text { neighborhood pixels. }\end{array}$ & No & Sobel & None & $\begin{array}{c}\text { Straight edges, } \\
\text { corner gets sharper. }\end{array}$ \\
\hline 4 & $\begin{array}{c}\text { Setayesh and } \text { et al. } \\
\text { ACM 2011. }\end{array}$ & $\begin{array}{c}\text { Particle swarm } \\
\text { optimization. }\end{array}$ & No & Canny & PSNR & $\begin{array}{c}\text { Computationally } \\
\text { expensive. }\end{array}$ \\
\hline
\end{tabular}

\section{EXPERIMENTAL RESULTS, CONCLUSION AND FUTURE SCOPE.}

We simulated algorithm using MATLAB 7.11 (R2010b). Experimental results are shown in figure 1 and figure 2. BSD images and respective ground truths are used for qualitative comparison of algorithms. Generally real images comprises of both strong and weak edges. The proposed method gives both strong and weak edges having different thresholds. In future, comparison with other methods can be checked.

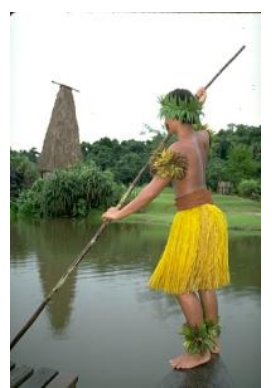

(a)

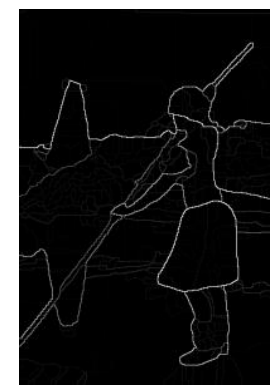

(b)

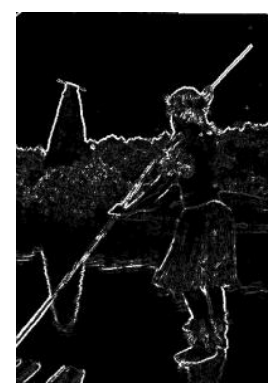

(c)
Figure 1: Column (a) Original BSD image, Column (b) Ground truth, Column (c) Proposed approach

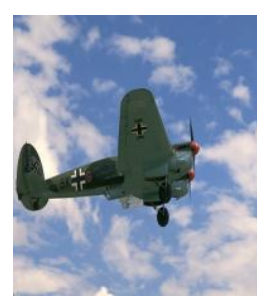

(a)

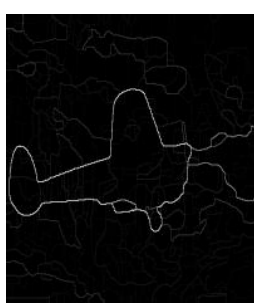

(b)

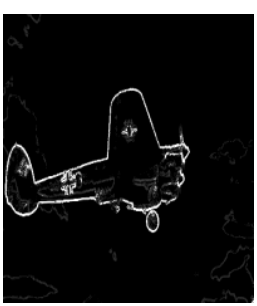

(c)
Figure 2: Column (a) Original BSD image, Column (b) Ground truth, Column (c) Proposed approach

\section{REFERENCES}

[1] J Patel and et al., "Fuzzy Inference based Edge Detection System using Sobel and Laplacian of Gaussian Operators" ICWET'11, ACM 978-1-4503-0449-8, pp 694-697, February 25-26, 2011.

[2] Mahdi Setayesh and et al., "Detection of Continuous, Smooth and Thin Edges in Noisy Images Using Constrained Particle Swarm Optimization" ACM 978-14503-0557-0, GECCO'11, Dublin, Ireland, pp 45-52, July 12-16, 2011.

[3] Abdallah A. Alshennawy, and Ayman A. Aly "Edge Detection in Digital Images Using Fuzzy Logic Technique", World Academy of Science, Engineering and Technology pp 178-186, 2009.

[4] Kaustubha Mendhurwar and et al., "Edge-Detection in Noisy Images Using Independent Component Analysis", ISRN Signal Processing, 9 pages, February 2011.

[5] Song Wang and et al., "Evaluating Edge Detection through Boundary Detection" EURASIP Journal on Applied Signal Processing, Article ID 76278, Pages 115, June 2006.

[6] Bhadauria H S and Dewal M L, "Comparison of Edge Detection Techniques on Noisy Abnormal Lung CT Image before and after Using Morphological Filter" International Journal of Advanced Engineering \& Application, pp 272-275, Jan. 2010.

[7] Raman Maini and Himanshu Aggarwal, "Study and Comparison of Various Image Edge Detection Techniques", International Journal of Image Processing (IJIP), Volume 3 pp-1-12, 2010.

[8] Chandra Sekhar Panda and Srikanta Patnaik, "Filtering Corrupted Image and Edge Detection in Restored Grayscale Image Using Derivative Filters" International Journal of Image Processing (IJIP), Volume 3, pp 105119, 2010. 
[9] J. Canny.: "A Computational Approach to Edge Detection." IEEE Trans, Pattern Anal. Mach. Intell. 8 (6) 679-687, 1986.
[10] Raman Maini , J.S.Sohal," Performance Evaluation of Prewitt Edge Detector for Noisy Images", GVIP Journal, Volume 6,December 2006. 